\title{
Reaction kinetics and mechanisms of organosilicon fungicide flusilazole with sulfate and hydroxyl radicals
}

\author{
D. Fabio Mercado a, Larisa L.B. Bracco a , Antonio Arques ${ }^{\text {b }}$, Mónica C. Gonzalez a , \\ Paula Caregnato ${ }^{\text {a, * }}$ \\ a Instituto de Investigaciones Fisicoquímicas Teóricas y Aplicadas (INIFTA), CCT-La Plata-CONICET, Universidad Nacional de La Plata, Casilla de Correo 16, \\ Sucursal 4, 1900, La Plata, Argentina \\ ${ }^{\mathrm{b}}$ Grupo de Procesos de Oxidación Avanzada, Departamento de Ingeniería Textil y Papelera, Universitat Politècnica de València, Campus de Alcoy, Plaza \\ Ferrandiz y Carbonell s/n, 03801, Alcoy, Spain
}

\section{H I G H L I G H T S}

- Flusilazole degradation by photoFenton process with solar simulator.

- CG-MS by-products detected show cleavage between silicon and triazole ring.

- A charge transfer reaction mechanism from the fungicide to the radicals is proposed.

\section{A R T I C L E I N F O}

\section{Article history:}

Received 15 June 2017

Received in revised form

19 August 2017

Accepted 27 September 2017

Available online 28 September 2017

Handling Editor: Jun Huang

\section{Keywords:}

Flusilazole

Fungicide degradation

Degradation mechanism

Sulfate radical

Hydroxyl radical

Photo-fenton

\section{G R A P H I C A L A B S T R A C T}

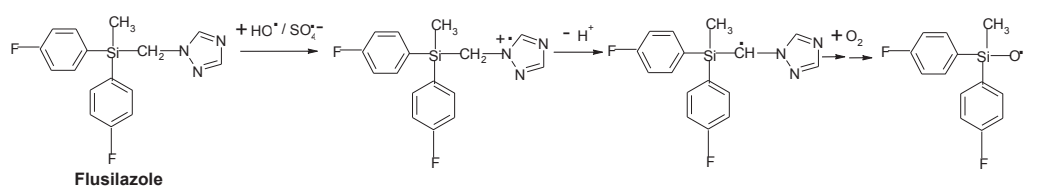

\begin{abstract}
A B S T R A C T
Flusilazole is an organosilane fungicide used for treatments in agriculture and horticulture for control of diseases. The reaction kinetics and mechanism of flusilazole with sulfate and hydroxyl radicals were studied. The rate constant of the radicals with the fungicide were determined by laser flash photolysis of peroxodisulfate and hydrogen peroxide. The results were $2.0 \times 10^{9} \mathrm{~s}^{-1} \mathrm{M}^{-1}$ for the reaction of the fungicide with $\mathrm{HO} \cdot$ and $4.6 \times 10^{8} \mathrm{~s}^{-1} \mathrm{M}^{-1}$ for the same reaction with $\mathrm{SO}_{4}{ }^{-}$radicals. The absorption spectra of organic intermediates detected by laser flash photolysis of $\mathrm{S}_{2} \mathrm{O}_{8}^{2-}$ with flusilazole, were identified as $\alpha$-aminoalkyl and siloxyl radicals and agree very well with those estimated employing the time-dependent density functional theory with explicit account for bulk solvent effects. In the continuous photolysis experiments, performed by photo-Fenton reaction of the fungicide, the main degradation products were: (bis(4-fluorophenyl)-hydroxy-methylsilane) and the non-toxic silicic acid, diethyl bis(trimethylsilyl) ester, in ten and twenty minutes of reaction, respectively.
\end{abstract}

(C) 2017 Published by Elsevier Ltd.

\section{Introduction}

Advanced oxidation processes (AOPs), like $\mathrm{UV} / \mathrm{S}_{2} \mathrm{O}_{8}^{2-}$ and Fenton, have attracted interest for the degradation of organic compounds in wastewater, such as pesticides (Carra et al., 2016;

\footnotetext{
* Corresponding author.

E-mail address: caregnato@inifta.unlp.edu.ar (P. Caregnato).
}

Navarro et al., 2011). This is especially true in the case of the use of light-induced reactions in water treatments. The photo-assisted Fenton reaction ("photo-Fenton" reaction) typically gives faster rates and a higher degree of mineralization than the thermal reaction and can take the advantage of light in the solar spectral region (Faust and Hoigné, 1990). In photo-Fenton process $\mathrm{Fe}^{2+}$ ions are oxidized by $\mathrm{H}_{2} \mathrm{O}_{2}$ and one equivalent $\mathrm{HO} \cdot$ is produced. The obtained $\mathrm{Fe}(\mathrm{OH})^{2+}$, which is predominant in acidic conditions, act as the light absorbing species that produce another radical while 
the initial $\mathrm{Fe}^{2+}$ is regained (Kim and Vogelpohl, 1998). Persulfate reaction mechanism is based on the generation of the strong sulfate radical $\left(\mathrm{SO}_{4}{ }^{-}\right)$. One mole of this reagent can be activated to generate $2 \mathrm{~mol}$ of sulfate radical under UV irradiation. The sulfate radical is known to be a very strong oxidant, i.e. $\mathrm{E}\left(\mathrm{SO}_{4}{ }^{-}{ }^{-}\right.$ $\mathrm{SO}_{4}^{2-}$ ) $=2.43 \mathrm{~V}$ vs. NHE (Criquet and Leitner, 2009) for degrading organic contaminants in wastewater (Wang and Liang, 2014; Luo et al., 2017).

Flusilazole is the approved name for 1-[[bis(4-fluorophenyl) methyl]silyl]methyl]-1H-1,2,4-triazole (CAS No. 85509-19-9). It is a triazole family fungicide with a molecular structure shown in Scheme 1. It is a broad-spectrum fungicide, which exhibits curative and preventative activities and is recommended for use in agriculture and horticulture (T. R. Roberts and Hutson, 1990).

Pesticides can easily accumulate in plants, foods, water reservoirs and food chain, which could be triggered by indiscriminate use. Besides, some of them are resistant to the action of sunlight, temperature, water or microorganisms; as a result of this, plant tissue and environmental samples contain high levels of pesticides residues.

It was suggested that flusilazole is capable of inducing genotoxicity in plants in studies with higher plant models (Ozakca and Silah, 2013). Animal models in vitro and in vivo have been used to investigate the teratogenecity of flusilazole. Some studies reported marked maternal toxicity, growth retardation, and skeletal in rodent models, which contribute to alterations in fetal growth retardation and skeletal development (Farag and Ibrahim, 2007). Besides embryotoxic responses are critically dependent on the timing of exposure during rat embryo development (Dimopoulou et al., 2016).

Photolysis (artificial and natural sunlight) on soil surface and aqueous photodegradation is not an important mode of degradation for flusilazole (T. R. Roberts and Hutson, 1990). Despite flusilazole is a widely used fungicide, documented data on their degradation mechanism and intermediate metabolites is lacking. Differences in chemical reactivity between silicon and carbon compounds influence the degradation and oxidative metabolism of otherwise similar compounds. For instance, organic silicon compounds usually lead to naturally occurring silicates as final product, in sharp contrast with the carbon containing analogous compounds (Griessbach and Lehmann, 1999).

In this context, the aim of the present work is to investigate the kinetics and mechanism of the degradation of flusilazole initialed by $\mathrm{HO} \cdot$ and $\mathrm{SO}_{4}{ }^{-}$. These radicals have been generated by laser flash photolysis $\left(\lambda_{\text {exc. }}=266 \mathrm{~nm}\right.$ ) of $\mathrm{H}_{2} \mathrm{O}_{2}$ and $\mathrm{Na}_{2} \mathrm{~S}_{2} \mathrm{O}_{8}$, respectively. Also, continuous-irradiation experiments have been performed by photo Fenton reaction of the fungicide and the nature of the primary degradation products formed have been investigated by GC-MS analysis.

\section{Experimental}

Reagents. Flusilazole (1-((bis(4-fluorophenyl)methylsilyl)

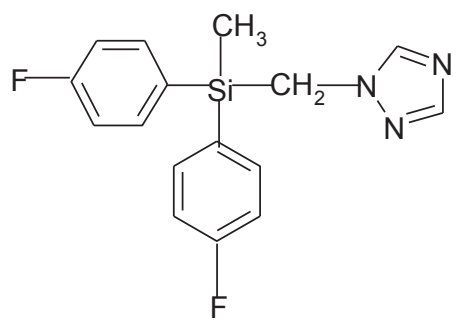

Scheme 1. Flusilazole.
methyl)-1H-1,2,4-triazole), was purchased from Sigma-Aldrich (Fluka). Sodium peroxodisulfate was obtained from Merck. Ferrous chloride tetrahydrate $\left(\mathrm{FeCl}_{2} \cdot 4 \mathrm{H}_{2} \mathrm{O}\right) 98 \%$ was obtained from Fisher Chemical. $\mathrm{H}_{2} \mathrm{O}_{2} 30 \%$ (w/w) in $\mathrm{H}_{2} \mathrm{O}$ was supplied by SigmaAldrich. Potassium thiocyanate was from Mallinckrodt.

Distilled water was passed through a Millipore system (>18 MX $\mathrm{cm},<20 \mathrm{ppb}$ of organic carbon).

Sample Preparation. Flusilazole (F) saturated aqueous solution was prepared to set up suspensions of lower concentrations by dilution. Oxygen-free and oxygen saturated solutions were obtained by bubbling the samples with argon or oxygen, respectively, for 20-30 min before use.

In continuous photolysis experiments the $\mathrm{pH}$ of the solution was adjusted to 3.0 using $\mathrm{HCl}$ and the sample was mixed using a magnetic stirrer during the process.

Laser Flash Photolysis (LFP) Experiments. LFP experiments were performed by excitation with the fourth harmonic of a Nd:YAG Litron laser ( $2 \mathrm{~ns}$ fwhm, $2 \mathrm{~mJ}$ per pulse at $266 \mathrm{~nm}$ ). The analyzing light from a $350 \mathrm{~W}$ Xe arc lamp was passed through a monochromator (PTI 1695) and detected by a 1P28 PTM photomultiplier. Due to the characteristics LFP detection system used, traces with $\lambda>650 \mathrm{~nm}$ and $\lambda<290 \mathrm{~nm}$ could not be detected within the experimental error. A cuvette of $10 \mathrm{~mm}$ path length was used for the sample container. Decays typically represented the average of 32 laser shots and were stored in a $500 \mathrm{MHz}$ Siglent digital oscilloscope. Solution absorbance was 0.5 at $266 \mathrm{~nm}$. Reactant concentrations were: $\left[\mathrm{Na}_{2} \mathrm{~S}_{2} \mathrm{O}_{8}\right]=1.0-2.5 \times 10^{-2} \mathrm{M}$ and flusilazole was in the range $8.49 \times 10^{6} \mathrm{M}-8.50 \times 10^{-5} \mathrm{M}$.

Freshly prepared solutions were used in order to avoid thermal reactions of peroxodisulfate and hydrogen peroxide with the substrate.

Bilinear regression analysis. For each experimental condition, several absorbance decay profiles at different detection wavelengths were taken. Absorbance is thus a function of wavelength and time. Taking advantage of the linearity of the absorbance with both, concentrations and absorption coefficients, a bilinear regression analysis was applied to the experimental absorption matrix in order to retrieve information on the minimum number of species and on their relative concentration profiles and absorption spectra (San Román and Gonzalez, 1998).

Time-dependent density functional theory calculations. Time dependent density functional calculations, TD-DFT, has been employed in numerous studies as a useful tool to characterize electronically excited states of a large number of molecules (Dell 'Arciprete et al., 2011; Arce et al., 2012). In this work, the hybrid B98 (Schmider and Becke, 1998) density functional combined with the $6-311++G(d, p)$ basis set, was used to interpret the spectra of the observed transient species. To account for solvent effects, the conductor-like polarizable continuum model, CPCM, was employed using a relative permittivity for $\mathrm{H}_{2} \mathrm{O}$ of 78.3553 (Barone and Cossi, 2001). In this way, the interaction between solvent and solute molecules was considered. All calculations have been carried out with the Gaussian 09 package (Frisch et al., 2009). To obtain the theoretical absorption spectrum it is firstly necessary a full optimization of the geometric parameters of the considered groundstate molecule. In all the cases, real frequencies were obtained indicating that molecular structures correspond to stable species. Next, the vertical electronic energies, the associated wavelengths of the band maxima, $\lambda_{\max }$, and oscillator strengths $f$ were computed at the abovementioned level of theory.

To compare the prediction with experimental data, theoretical bands were approached with individual Gaussian functions characterized with full width values $\sigma$ (at the 1/e height of the bands) and summed over all relevant electronic transitions (Cobos and Croce, 2010). As Fig. 3 shows, a satisfactory agreement between 
the experimental and the modeled spectra for all species are obtained using a standard value of $\sigma=0.21 \mathrm{eV}$.

\subsection{Chemical analysis}

The concentration of flusilazole was determined by HPLC and reaction products of fenton reactions were analyzed by GC-MS.

Samples were irradiated in a cylindrical glass reactor with a solar simulator (Oriel Instruments, Model 81160) equipped with a $300 \mathrm{~W}$ xenon lamp and a cut off $300 \mathrm{~nm}$ filter. The prepared solution was $5 \mathrm{ppm}$ of $\mathrm{Fe}^{2+}$ and $1.23 \times 10^{-3} \mathrm{M}$ of flusilazole. $50 \mu \mathrm{L}$ of $\mathrm{H}_{2} \mathrm{O}_{2}$ was added to a volume of $250 \mathrm{~mL}$.

HPLC analysis. In order to follow the concentration of the flusilazole in the reaction system, a Merck Hitachi XL Autosystem D-7000 chromatograph with a diode array detector was used. The column used to separate the flusilazole was a LiChroCART ${ }^{\circledR} 125-4$ with reverse phase LiChrospher ${ }^{\circledR} 100$ RP-18 $(5 \mu \mathrm{m})$ from Merck. Samples of $0.5 \mathrm{~mL}$ were directly taken from the reaction system and they were diluted with $0.5 \mathrm{~mL}$ of methanol. The injection volume was $80 \mu \mathrm{L}$. As mobile phase a mixture of water:methanol $(20: 80)(\mathrm{v} / \mathrm{v})$ were used in a flow $0.8 \mathrm{~mL} \mathrm{~min}-1$. The detection wavelength was $230 \mathrm{~nm}$ and the retention time for the flusilazole was about $5.1 \mathrm{~min}$.

GC-MS. After selected periods of irradiation (10 or $20 \mathrm{~min}$ ), the reactor was emptied and the treated solution was concentrated by means of solid phase extraction: $100 \mathrm{~mL}$ of the aqueous solution were flown though a LiChrolut EN $200 \mathrm{mg}$ (Merck) cartridge and the adsorbed organics were recovered with $3 \mathrm{~mL}$ of methanol. A GCMS-QP2010S (Shimadzu) gas chromatograph equipped with a quadrupole mass analyzer was employed to identify major intermediates formed along the process. The temperature program for GC analysis involved a heating method with a constant ramp from $60{ }^{\circ} \mathrm{C}$ to $250{ }^{\circ} \mathrm{C}$ at a rate of $5{ }^{\circ} \mathrm{C} / \mathrm{min}$ rate. A Meta X5 Teknokroma column was used. The retention time for the flusilazole and the observed products are listed in Table 1.

\section{Results and discussion}

\subsection{Experiments with $\mathrm{HO} \cdot$ radicals}

\subsubsection{Continuous photolysis experiments}

Irradiation of $1.23 \times 10^{-3} \mathrm{M}$ aqueous solutions of flusilazole with the solar simulator, shows depletion of the fungicide with the photolysis time. According to Fig. 1, 5 min of irradiation were needed to achieve $80 \%$ abatement of flusilazole in the presence of 5 ppm $\mathrm{Fe}^{2+}$ and $50 \mu \mathrm{L}$ of $\mathrm{H}_{2} \mathrm{O}_{2}$ at $\mathrm{pH}=3$.

\subsubsection{Stable products identification}

Aqueous solutions containing $\mathrm{Fe}^{2+}, \mathrm{H}_{2} \mathrm{O}_{2}$, and flusilazole in the concentrations indicated above, were irradiated for 10 and $20 \mathrm{~min}$ with the solar simulator to detect the degradation products formed after reaction 2 .

Table 1 summarizes the GC-MS mass peaks and fragments detected for the degradation products of the fungicide.
After 20 min of photo-Fenton reaction with flusilazole, the GCMS peaks of $R_{t}<26.5$ min could not be identified due to the complex reaction system, which lead to a high number of reaction by-products reaching low concentrations.

\subsubsection{Kinetic measurements}

Hydroxyl radicals (HO•) were generated by LFP of $0.1 \mathrm{M} \mathrm{H}_{2} \mathrm{O}_{2}$ aqueous solution $\left(\lambda_{\text {exc. }}=266 \mathrm{~nm}\right)$, reaction 1 :

\begin{tabular}{ll}
\hline $\mathrm{H}_{2} \mathrm{O}_{2} \stackrel{h v}{\longrightarrow} \mathrm{HO}^{\bullet}$ & $1^{\prime}$ \\
$\mathrm{F}+\mathrm{HO}^{\cdot} \longrightarrow$ & 2 \\
\hline
\end{tabular}

The rate constant for the reaction of flusilazole with $\mathrm{HO} \cdot$ radicals (reaction 2) was assessed by the competition method $k$ $(\mathrm{F}+\mathrm{HO} \cdot)=2.0 \times 10^{9} \mathrm{~s}^{-1} \mathrm{M}^{-1}$ (Kozicki et al., 2003) (Dell 'Arciprete et al., 2009) (See Supplementary data). The concentration range of flusilazole solutions used was $0-1.12 \times 10^{-4} \mathrm{M}$.

A degradation mechanism is proposed for the reaction of hydroxyl radicals and flusilazole.

Tertiary amines are reactive sites for $\mathrm{HO} \cdot$ radical attack (Das and von Sonntag, 1986) (Dell 'Arciprete et al., 2009). The simplest oxidation process for a tertiary amine is single electron transfer from the non-bonding electron pair of the amine to form a radical cation, followed by a $\alpha-\mathrm{CH}$ bond cleavage or hydrogen atom transfer. The process will be denoted as hydrogen-atom transfer if the electron and proton acceptor are the same identity (Sumalekshmy and Gopidas, 2005; Suresh Das and V. Suresh, 2001).

Scheme 2 show a possible reaction pathway, which involves an initial electron transfer by $\mathrm{HO}$ radicals to yield a radical cation in the $\mathrm{N}$ tertiary atom of triazole ring followed by elimination of $\mathrm{H}^{+}$ ion to yield a more stable $\alpha$ aminoalkylradical.

\subsection{Experiments with $\mathrm{SO}_{4}^{*^{-}}$radicals}

It is not possible to detect organic intermediates generated by reaction of hydroxyl radicals with flusilazole using the indirect method. In order to confirm the first steps of the mechanism proposed in Scheme 2, LFP experiments initiating the oxidation of flusilazole with highly oxidative species such as sulfate radicals $\left(\mathrm{SO}_{4}{ }^{-}\right)$were performed.

\subsubsection{Kinetic measurements}

In LFP experiments of aqueous $1.0-2.5 \times 10^{-2} \mathrm{M}$ peroxodisulfate solutions, a transient specie was formed in the wavelength range of 330-500 $\mathrm{nm}$ (reaction 3). The obtained decay rate and spectrum are in agreement with those reported in the literature for $\mathrm{SO}_{4}{ }^{--}$(Choure et al., 1997).

\begin{tabular}{ll}
\hline $\mathrm{S}_{2} \mathrm{O}_{8}^{-2} \stackrel{h v}{\longrightarrow} 2 \mathrm{SO}_{4}^{--}$ & 3 \\
$\mathrm{~F}+\mathrm{SO}_{4}^{-} \longrightarrow$ & 4 \\
\hline
\end{tabular}

\begin{tabular}{ll}
\hline $\mathrm{Fe}^{2+}+\mathrm{H}_{2} \mathrm{O}_{2} \longrightarrow \mathrm{Fe}(\mathrm{OH})^{2+}+\mathrm{HO}^{\bullet}$ & 1 (Trovó et al., 2008; Kim and Vogelpohl, 1998) \\
$\mathrm{Fe}(\mathrm{OH})^{2+}+h v \rightarrow \mathrm{Fe}^{2+}+\mathrm{HO}^{\bullet}$ & \\
$\mathrm{HO}+\mathrm{F} \longrightarrow$ & 2 \\
\hline
\end{tabular}


Table 1

Degradation products.

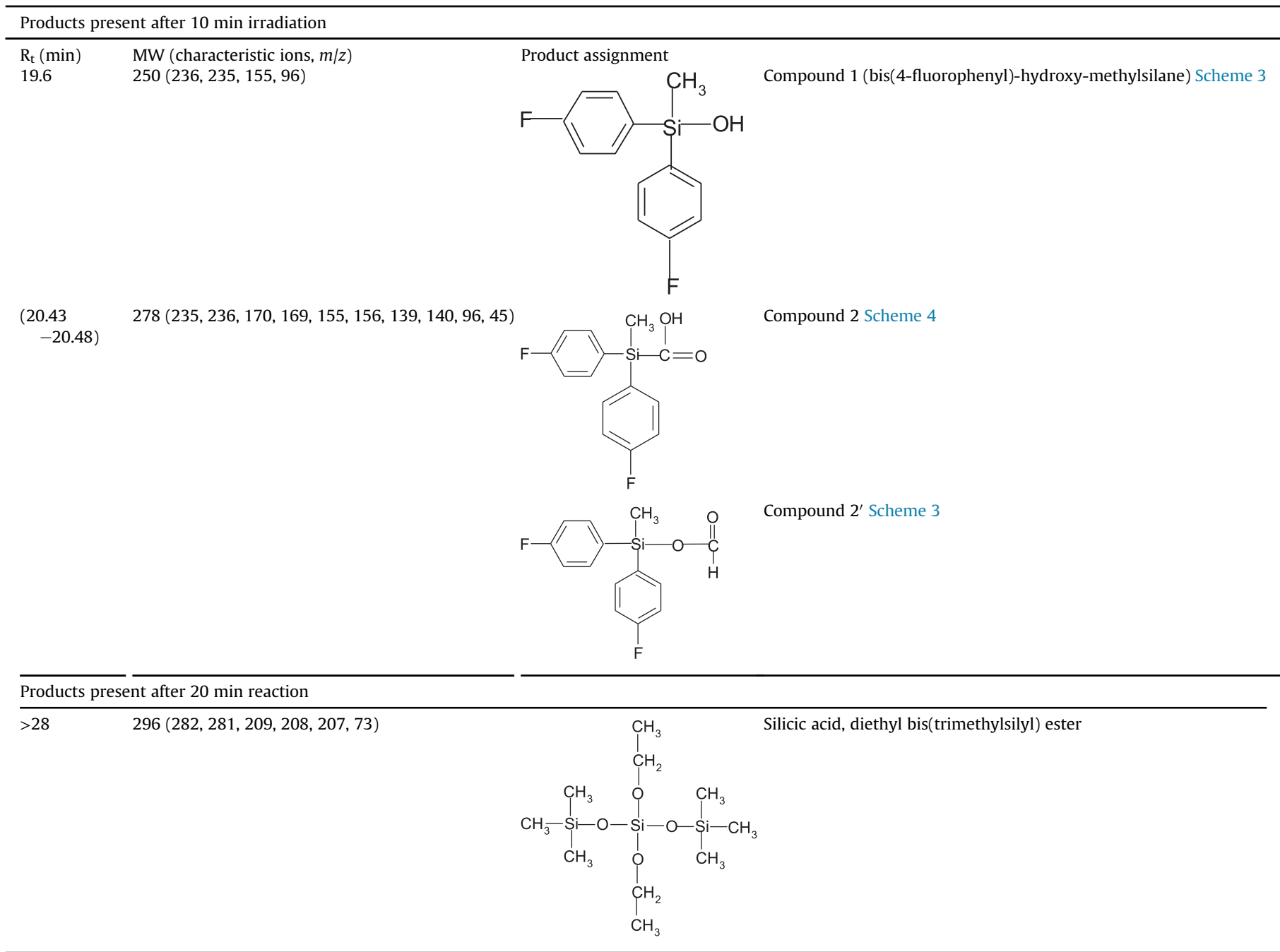

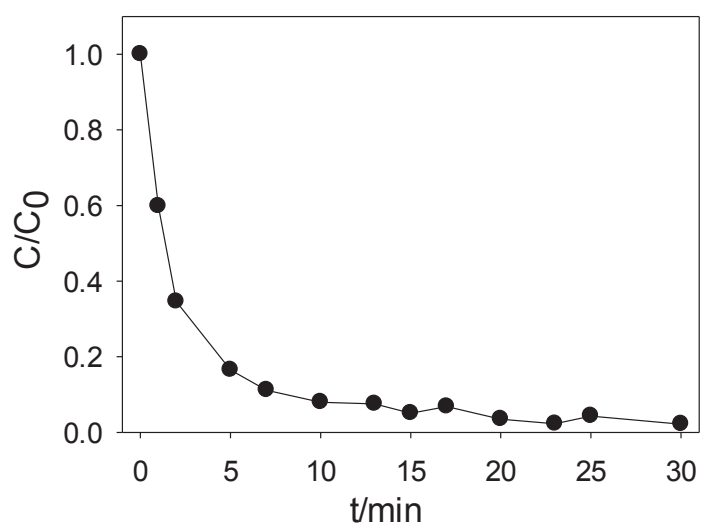

Fig. 1. Fungicide depletion $\left(1.23 \times 10^{-3} \mathrm{M}\right)$ in photolysis experiments with light of solar simulator at $\mathrm{pH}=3$.

The $\mathrm{SO}_{4}{ }^{-}-$radical absorbance decay at detection $\lambda(\Delta \mathrm{A})$, fit to Eqn (1) which shows both first and second-order components (See Supplementary data):

$$
\Delta A=\frac{a}{b(\lambda) \exp (a t)-c(\lambda)}
$$

Where: $a$ is the apparent first order decay constant $\left(K_{\mathrm{app}}\right)$, and $b(\lambda)=\left(a / \Delta \mathrm{A}_{0}\right)+c(\lambda)$. The second order constant $2 k / \varepsilon(\lambda)$ is calculated from $c(\lambda)=2 k / \varepsilon(\lambda) l$, where $\varepsilon(\lambda)$ is the absorption coefficient at a certain wavelength, and $l$ is the optical path. $\Delta \mathrm{A}_{0}$ is absorbance at $\mathrm{t}=0$.

Photolysis experiments of sodium persulfate aqueous solutions in the presence of flusilazole $\left(4.25 \times 10^{-5} \mathrm{M}>[\mathrm{F}]>8.47 \times 10^{-5} \mathrm{M}\right)$, showed formation of transient species in the wavelength range from 300 to $650 \mathrm{~nm}$. The decay kinetics of the traces observed strongly depend on wavelength. Therefore, a bilinear regression analysis was used to retrieve kinetic and spectroscopic information of the individual species in the reaction mixture.

Sulfate radical anion is the only specie that absorbs at $\lambda=450 \mathrm{~nm}$. Sulfate radical traces show a first order decay with an apparent rate constant, $\mathrm{k}_{\mathrm{app}}$, increasing with flusilazole concentration, as depicted in the inset of Fig. 2.

The slope of the straight line in Fig. 2, yields the rate constant $\mathrm{k}$ for the reaction of sulfate radicals with flusilazole (reaction 4) $\mathrm{k}$ $\left(\mathrm{F}+\mathrm{SO}_{4^{-}}\right)=(4.6 \pm 0.4) \times 10^{8} \mathrm{~s}^{-1} \mathrm{M}^{-1}$. 

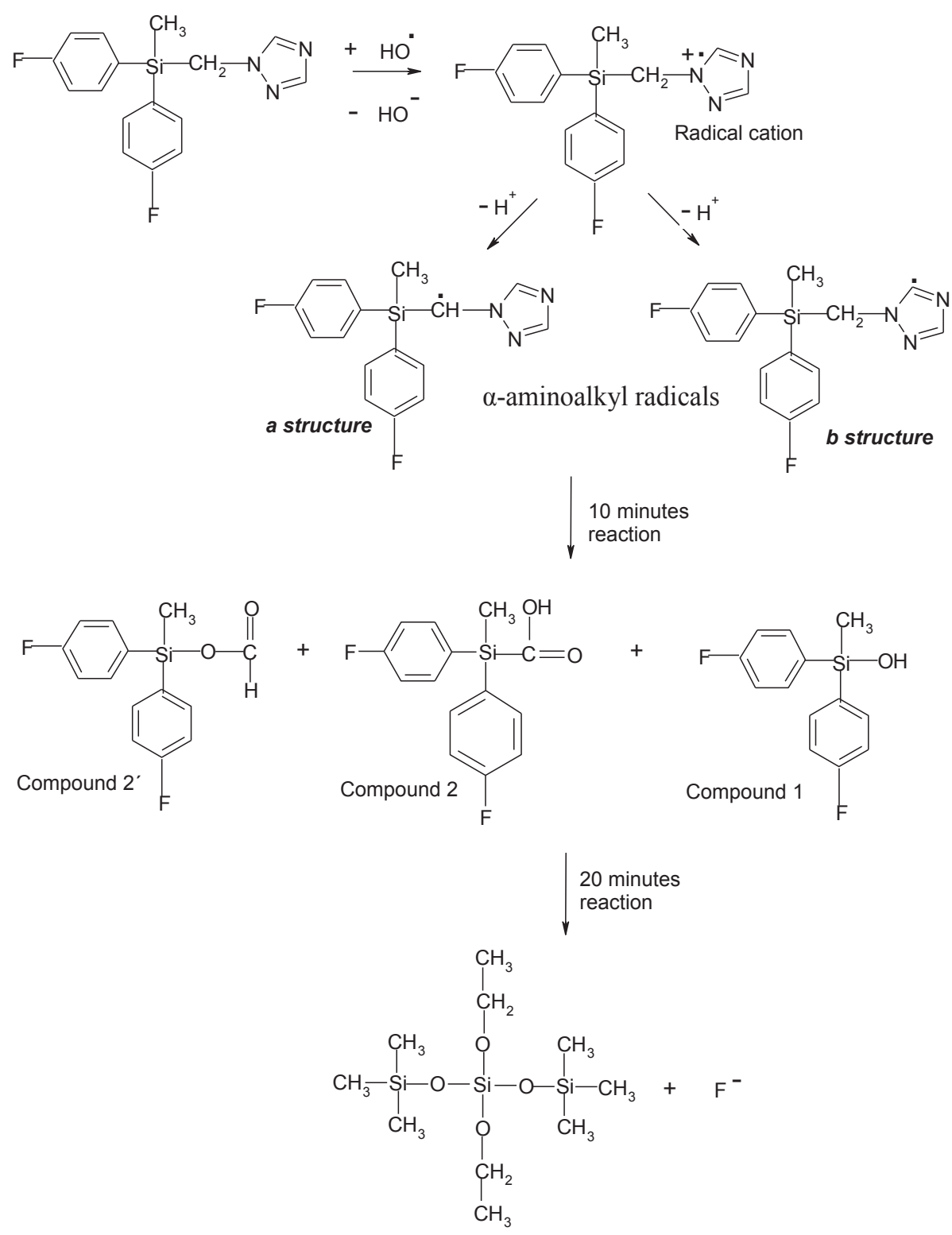

Scheme 2.

3.2.2. Intermediates formed after the reaction of $\mathrm{SO}_{4}{ }^{-}{ }^{-}$radicals with flusilazol

At high flusilazole concentrations the decay rate of $\mathrm{SO}_{4}{ }^{-}$radicals becomes too fast to be observed in our time resolution range. On the other hand, laser flash photolysis of flusilazole solutions in the absence of persulfate showed no traces, within our experimental error, in the UV and visible range. Therefore, under these conditions, the observed traces may be assigned to organic transients formed after reaction of $\mathrm{SO}_{4}{ }^{-}$with flusilazole (reaction 4).

To study the spectra and decay rates of the organic intermediates, experiments were performed with solutions containing the highest concentration of flusilazole used $\left(8.47 \times 10^{-5} \mathrm{M}\right)$ and $2.5 \times 10^{-2} \mathrm{M}$ of persulfate.

A bilinear analysis of the absorbance matrix (see Experimental Section above), shows that the system could be described by two absorbing species in the wavelength range from 290 to $640 \mathrm{~nm}$, named transient 1 and transient 2 . The first transient absorbs at wavelengths of $300 \mathrm{~nm}$, and the second one has two maxima at
350-360 $\mathrm{nm}$ and $640 \mathrm{~nm}$, respectively.

In order to gain further insight into the transients' nature, the reaction with molecular oxygen was investigated. To that purpose, LFP experiments under argon, air and oxygen saturated atmosphere with $2.5 \times 10^{-2} \mathrm{M} \mathrm{S}_{2} \mathrm{O}_{8}^{2-}$ solutions and $8.47 \times 10^{-5} \mathrm{M}$ of flusilazole were performed. The absorption spectra of the organic transient in the range $300-400 \mathrm{~nm}$ (transient 1 ), were similar in all three cases, within the error of the determination (See Fig. S1 at Supplementary data). The decay profiles of this transient fit to a mixed first and second order reaction rate law in the presence of oxygen (absorbance traces fit to Eqn (1)). Mainly a second order decay was observed in Ar- saturated solutions (see equation at Supplementary data). The first order decay rate constant was $2.2 \times 10^{3} \mathrm{~s}^{-1}$ and $3.4 \times 10^{3} \mathrm{~s}^{-1}$ in air- and oxygen-saturated samples, respectively. The second order component $2 \mathrm{k} / \varepsilon_{(300 \mathrm{~nm})} \sim 6 \times 10^{6} \mathrm{~cm} \mathrm{~s}^{-1}$ was independent on the presence of oxygen. The presence of a second order term in the decay traces might indicate a recombination of transient 1. 


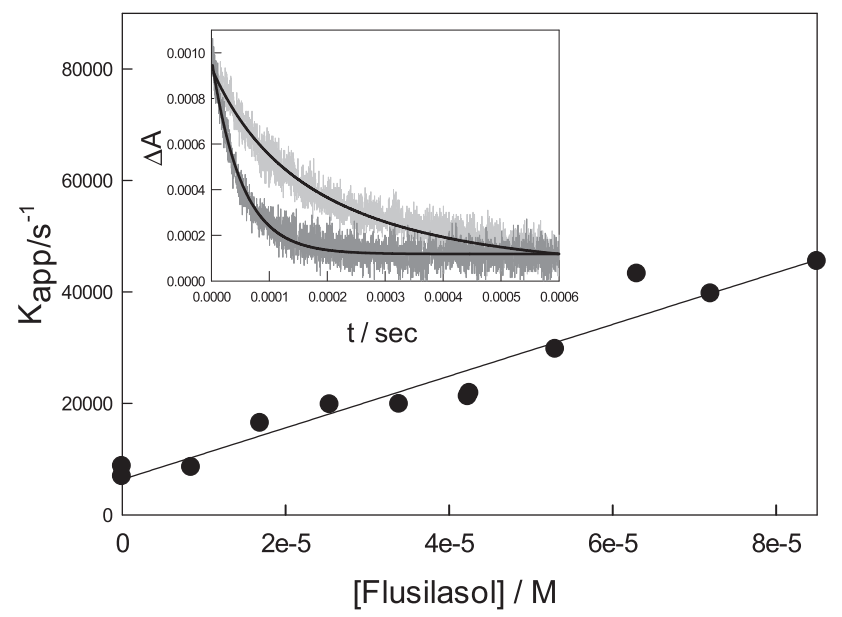

Fig. 2. Apparent rate constants, $K_{a p p} v s$. [F] obtained in experiments with $2.5 \times 10^{-2} \mathrm{M}$ sodium peroxodisulfate $\mathrm{Na}_{2} \mathrm{~S}_{2} \mathrm{O}_{8}$ aqueous solutions. Inset: Absorbance profiles at $450 \mathrm{~nm}$ obtained in experiments with $2.5 \times 10^{-2} \mathrm{M}$ peroxodisulfate $\mathrm{S}_{2} \mathrm{O}_{8}{ }^{2-}$ solutions in the presence (dark grey curve) and absence (light grey curve) of $4.25 \times 10^{-5} \mathrm{M}$ of F. The full lines stand for the fittings to Eqn (1).

The second transient had two absorption maxima at $350 \mathrm{~nm}$ and $640 \mathrm{~nm}$ with a decay profile that fits a mixed first and second order equation (Eqn (1)). No dependence of both first and second order constants with the concentration of dissolved oxygen was observed (see Table 2). However, the absorbance intensity of the second transient was dependent on the concentration of dissolved oxygen.

The one-electron charge transfer reaction from amine nitrogen to sulfate radicals to yield a radical cation in the $\mathrm{N}$ atom has been reported (Dell 'Arciprete et al., 2011). On the other hand, the rate constants for the $\mathrm{SO}_{4}{ }^{--}$hydrogen-abstraction from $\mathrm{C}-\mathrm{H}$ bonds were smaller than those measured here for the reactions of sulfate radical with the fungicide $\left(10^{5}\right.$ to $10^{7} \mathrm{~s}^{-1} \mathrm{M}^{-1}$ ) (Neta et al., 1988).

Nitrogen-centered radical cations do not efficiently react with molecular oxygen, as observed in other organic transients (Bosio et al., 2005; Dell'arciprete et al., 2007). It is discussed in literature that $\alpha$-aminoalkyl radicals are formed after the elimination of $\mathrm{H}^{+}$ from nitrogen-centered radical cations; this $\alpha$-aminoalkyl radicals are highly stabilized by the free electronic pair of the vicinal nitrogen (Padmaja et al., 1993; Luke et al., 2003; Ito et al., 2009). Considering that the amine-type nitrogen atom in the triazole moiety of flusilazole present $\mathrm{H}$-atoms $\alpha$ to nitrogen, identification of the observed transients as $\alpha$-aminoalkyl radicals is strongly suggested. Furthermore, $\alpha$-aminoalkyl radicals show significant absorbance up to $500 \mathrm{~nm}$ and react with molecular oxygen (Dell 'Arciprete et al., 2009; Hiller and Asmus, 1983; Lalevée et al., 2007), in agreement with the behavior of the first transient herein observed.

The second transient signal grows quickly, reaching its maximum value about $13 \mu$ s after the laser shot, and it decays within $500 \mu$ s (See Fig. S3 at Supplementary data). Besides, its formation depends on the concentration of dissolved oxygen in the sample. This behavior may be explained by a reaction mechanism in which this transient is formed via the reaction of the first

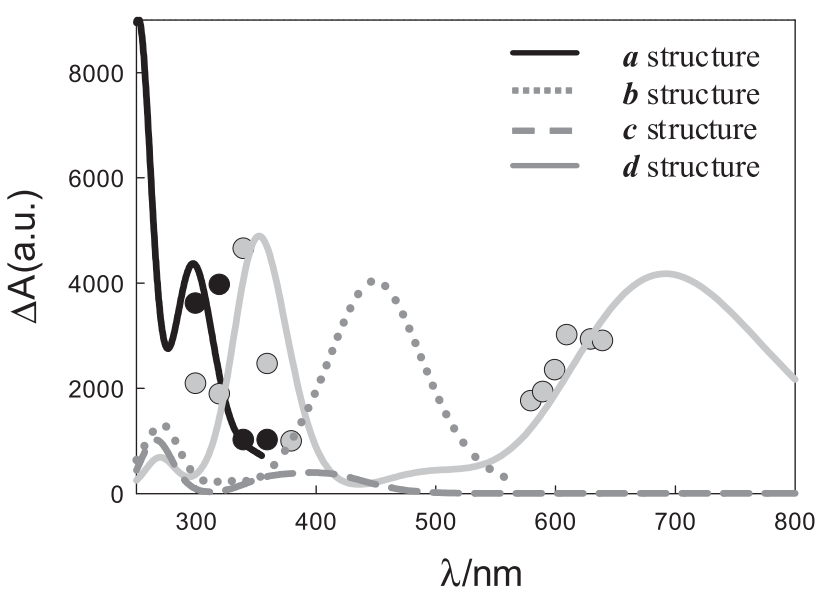

Fig. 3. Absorption spectra in arbitrary units of transient 1 (black circles) and transient 2 (grey circles) obtained at $1 \times 10^{-5} \mathrm{sec}$ from bilinear analysis of LFP experiments with $2.5 \times 10^{-2} \mathrm{M} \mathrm{S}_{2} \mathrm{O}_{8}^{2-}$ and $8.47 \times 10^{-5} \mathrm{M}$ Flusilazole in argon saturated solutions. The full, dotted and dashed lines stand for the calculated TD-DFT spectra.

transient with oxygen. Peroxyl radicals generated by reaction of $\alpha$ aminoalkyl radicals with oxygen could lead to the formation of siloxyl radicals, which are assigned to the second transient, as will be discussed later in the manuscript.

\subsubsection{Reaction pathways}

As discussed before, a charge transfer pathway leads to the formation of sulfate anions and the radical cation of flusilazole, which upon elimination of $\mathrm{H}^{+}$leads to $\alpha$-aminoalkyl radical.

To help identify the nature of the observed transients, the TDDFT spectra of $\alpha$-aminoalkyl radicals in carbon (structures $a$ and b) and the radical cation were calculated.

The coincidence obtained between the experimental first transient spectrum and those calculated for the $a$ structure of $\alpha$-aminoalkyl radicals, indicates that the observed transient may be assigned to the specie where carbon radical lies in the carbon atom vicinal to silicon in flusilazole molecule (Fig. 3). Radical cation in the $\mathrm{N}$ triazole atom is proposed in the first reaction step of Scheme 2. A reactive intermediate with a TD-DFT spectra absorption bellow $240 \mathrm{~nm}$ with $\lambda_{\text {max. }}=210 \mathrm{~nm}$, was not detectable in the time window of our experimental LFP setup.

Calculations for the $b$ structure of $\alpha$-aminoalkyl radical in carbon, shows a spectrum with a low absorption coefficient at $300 \mathrm{~nm}$ (Fig. 3).

The mechanism discussed above strongly confirms that the more reactive group of flusilazole is the triazole ring, as was proposed according to the by-products detected by GC-Mass in photoFenton reactions.

The $\alpha$-aminoalkyl radicals $(-\mathrm{HC} \cdot-\mathrm{N}<$ ) (Hiller and Asmus, 1983; Baciocchi et al., 2004) may either further react with molecular oxygen to yield peroxyl radicals (c structure), or recombine leading to the eventual production of flusilasole-amine dimer (Hasegawa et al., 1988) (See Scheme 3).

Peroxyl radicals (c structure) may produce siloxyl radicals through a mechanism that involves silicon pentacoordinated

Table 2

First order decay component $(a)$ and second order one $(b)$ obtained from the fit of decay traces of transient 1 and 2 by Eqn (1).

\begin{tabular}{|c|c|c|}
\hline & $a$ & $b=2 \mathrm{k} / \varepsilon(\lambda)$ \\
\hline Transient $1\left(\lambda_{\max } \sim 300 \mathrm{~nm}\right)$ & $\begin{array}{l}2.2 \times 10^{3} \mathrm{~s}^{-1} \text { (Air) } \\
3.4 \times 10^{3} \mathrm{~s}^{-1} \text { (bubbling oxygen) }\end{array}$ & $6 \times 10^{6} \mathrm{~cm} \mathrm{~s}^{-1}$ (bubbling $\mathrm{Ar}$, air and oxygen) \\
\hline Transient $2\left(\lambda_{\max } \sim 350\right.$ and $\left.640 \mathrm{~nm}\right)$ & $1 \times 10^{4} \mathrm{~s}^{-1}$ (bubbling Ar, air and oxygen) & $1 \times 10^{6} \mathrm{~cm} \mathrm{~s}^{-1}$ (bubbling Ar, air and oxygen) \\
\hline
\end{tabular}


intermediates as shown in Scheme 3. A similar mechanism was proposed by Corriu and co-workers for the hydrolysis of tetracoordinate silicates initiated by a nucleofilic attack leading to pentacoordinate silicon intermediate (Corriu et al., 1991).

Formation of transient $d$ ( $d$ structure) is strongly suggested, due to the high affinity of oxygen to silicon. $\mathrm{Si}-\mathrm{O}$ - radical could be depleted by reaction with hydrogen peroxide or other hydrogen donor in the media, leading to the formation of silanol.

The TD-DFT calculated spectra of peroxyl radical (structure $c$ ), has a wavelength maximum around $270 \mathrm{~nm}$, not observed in the experimental conditions of this setup. However, the second transient with $\lambda_{\max }$ at 350 and $640 \mathrm{~nm}$, is very similar to the one calculated called $d$ radical which it is also shown in Fig. 3 and may be assigned to that specie.

\subsection{Reaction of $\mathrm{HO}$ - radicals with flusilazol in continuous photolysis experiments. Reaction pathways}

Based on the detailed reaction mechanism for the first steps of reactions of $\mathrm{SO}_{4}{ }^{-}-$with flusilazole with identification of organic transients formed, a complete pathway for the initial photochemical products and primary steps of $\mathrm{HO} \cdot$ radical oxidation of flusilazole is proposed in Scheme $4 \mathrm{y} 5$ yielding compound 1, compound 2 and $2^{\prime}$ (GC-MS products).

The proposed mechanism is further supported by the fact that the rate constants reported for these reactions are on the order of those found here for the reaction of $\mathrm{HO} \cdot$ with the fungicide (Hiller and Asmus, 1983; Ross et al., 1998).

As shown in Scheme 4, the proposed reaction mechanism might involve the formation of silicon pentacoordinated intermediates after reaction of the $\alpha$-aminoalkyl radical with oxygen. This intermediate may explain the formation of identified products 1 and $2^{\prime}$. Besides, compound 1 could be produced by hydrolysis of compound $2^{\prime}$ (Tuazon et al., 2000) or by depletion of $\mathrm{Si}-\mathrm{O} \cdot$ radical with a hydrogen donor, such as hydrogen peroxide. Siloxyl radical intermediate could be proposed considering that the reaction mechanism with hydroxyl radical is analog to that described of flusilazole with sulfate radical (see Schemes 2 and 3).

Disproportionation reaction of peroxyl radicals (Scheme 5), may lead to the formation of hydroxyl and keto derivatives of flusilazole, neither of which was detected by GC-MS spectroscopy. Compound 2 detected, is justified by hydroxyl radical attack on triazole ring of keto derivatives of flusilazole, followed by hydrolysis.

The observation that no nitrogen derivates were detected by GCMS could be understood by a fast rupture of silicon pentacoordinated intermediates followed by oxidation of the triazole ring (Lhomme et al., 2007; Guillard et al., 2002; Le Campion et al., 1999).

Twenty minutes photo-fenton reaction with flusilazole leads to the formation of products with higher molecular weight than flusilazole. GC-MS spectra for retention times $>28$ min showed formation of compounds containing $\mathrm{Si}-\mathrm{O}-\mathrm{C}$ and $\mathrm{Si}-\mathrm{O}-\mathrm{Si}$ groups, such as silicic acid, diethyl bis(trimethylsilyl) ester. The main route to obtain siloxane functional group is by condensation of two silanols like those formed in the first minute's fenton reaction, as showed in Scheme 3. Besides, molecules containing $\mathrm{Si}-\mathrm{O}-\mathrm{C}$ groups are proposed to be generated as by-product in the same scheme (compound $2^{\prime}$ ). Silicic acid, diethyl bis(trimethylsilyl) ester has no fluorine content in its structure. It indicates that between ten and twenty minutes of photo-Fenton process, loss of fluoride starts taking place.

GC-MS peaks of $R_{t}<26.5$ min are not easy identified in 20 min reaction. This might be because the reaction system is too complex

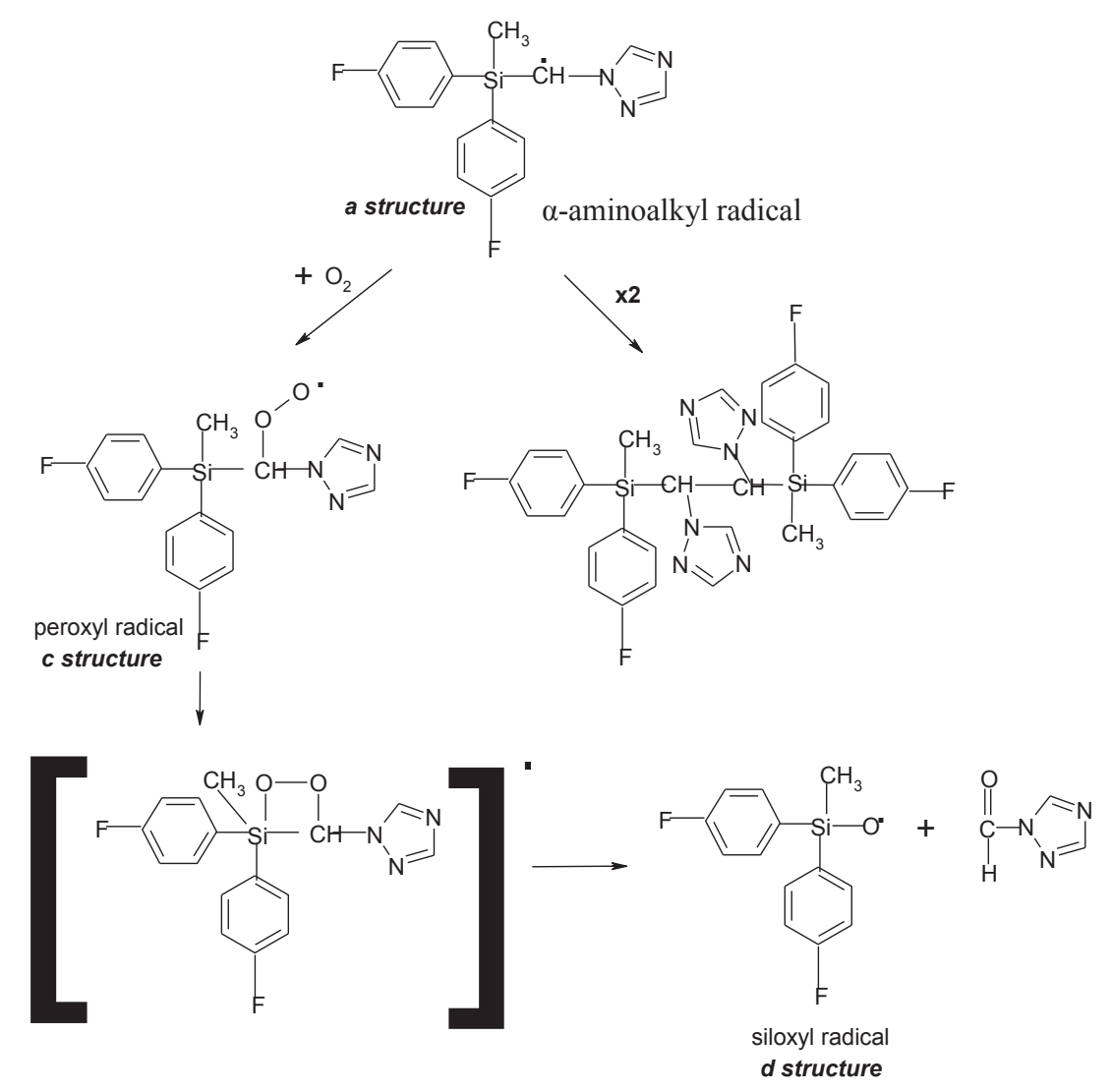

Scheme 3. 


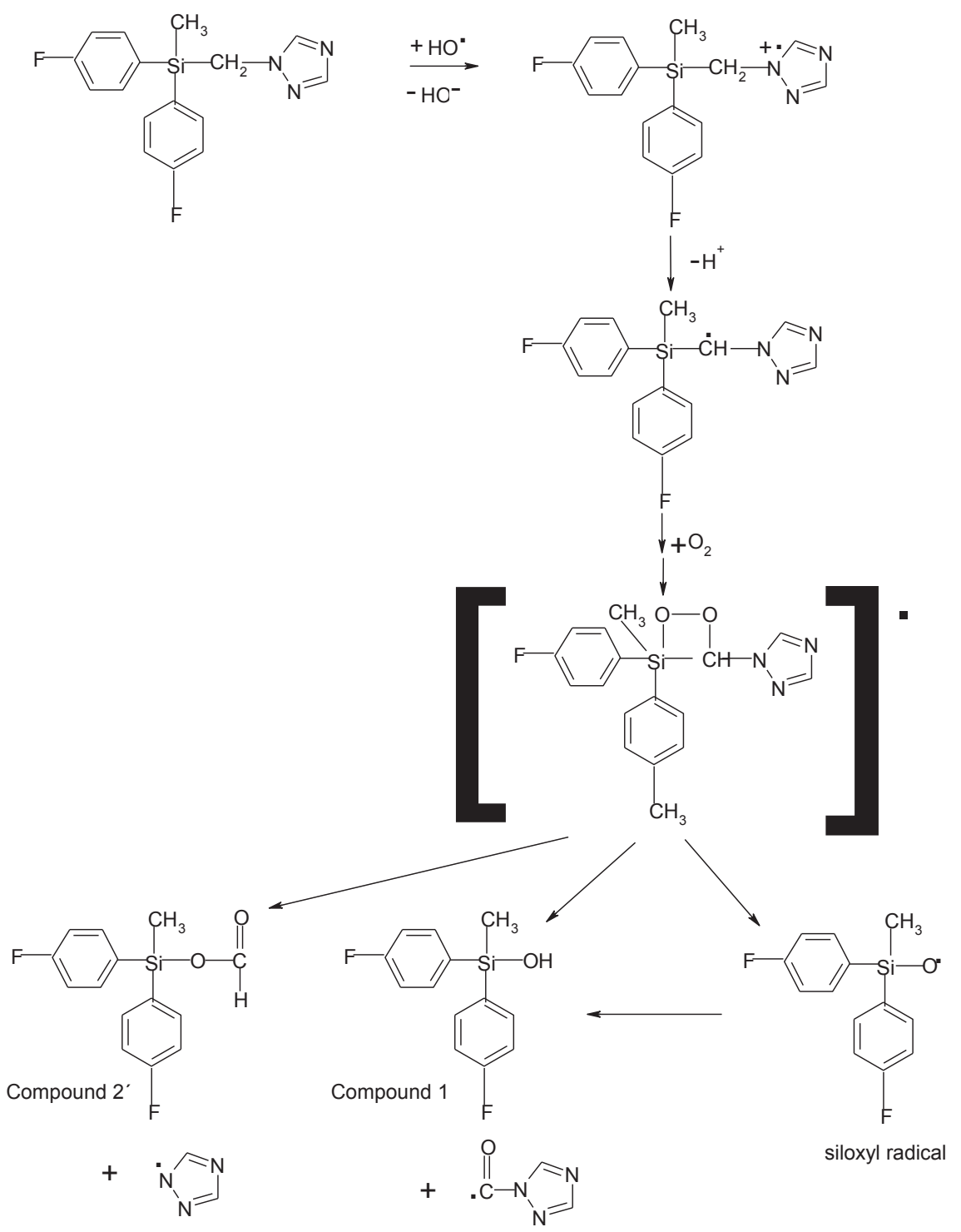

Scheme 4.

to recognize low molecular weight by-products. Amat et al. (2009) described a similar complex system were a great number of low molecular weight CG-MS products generated by fast cleavage of molecules, which did not allow the elucidation of a detailed mechanism for the degradation of the chemicals.

In flusilazole metabolism in rats, goat, hens, apples, wheat, grapes and soil (Mastovska, 2007; T. R. Roberts and Hutson, 1990) and in environmental fate studies of the insecticide, the main degradation product detected was [Bis(4-fluorophenyl)methyl] silanol $\left(\mathrm{C}_{13} \mathrm{H}_{12} \mathrm{~F}_{2} \mathrm{OSi}\right)$ of molecular weight $250 \mathrm{~g} / \mathrm{mol}$. Other polar metabolites containing silanol groups were detected in the tissue residues and excretion samples analyzed in rats, goats, and hens.

Silicic acid, diethyl bis(trimethylsilyl) ester is a non toxic compound that is found in root and inner bark extract of some medicinally important plants against human pathogens with antioxidant activity (Anjaneyulu et al., 2013; Hosseinihashemi et al., 2015; Kathirvel et al., 2014).

This compound is detected in GC-MS spectrum after the photo Fenton degradation of flusilazole, what suggests that degradation of that organosilicon fungicide by this process is an important route of decomposition yielding non toxic by-products.
Cleavage between the silicon and the triazole ring to form the silanol is the major metabolic route in plants, which may be further metabolized to the silane diols or to disiloxane (Mastovska, 2007). The results in twenty minutes photo fenton experiments showed that a siloxane (a silane ether) is produced, in line with the reported metabolic route.

\section{Conclusions}

The fungicide flusilazole chemically react with hydroxyl radical and sulfate radical anion with rate constants of $2.0 \times 10^{9} \mathrm{~s}^{-1} \mathrm{M}^{-1}$ and $4.6 \times 10^{8} \mathrm{~s}^{-1} \mathrm{M}^{-1}$, respectively.

Both reactions involve a charge transfer from the fungicide to the radicals, characteristic for tertiary amines. Proton elimination from the ethyl carbon vecinal to the triazole $N$ atom yields $\alpha$-aminoalkyl radicals detected as the main transients formed. The absorption spectra of the transients observed in the range $300-700 \mathrm{~nm}$ could be assigned to carbon centered radicals and siloxyl radicals in accordance to the DFT calculated spectra and with data reported by Dell 'Arciprete et al. (2011). The amidine nitrogen of the molecule is the preferred site of attack by $\mathrm{HO}$ and $\mathrm{SO}_{4}{ }^{--}$ 


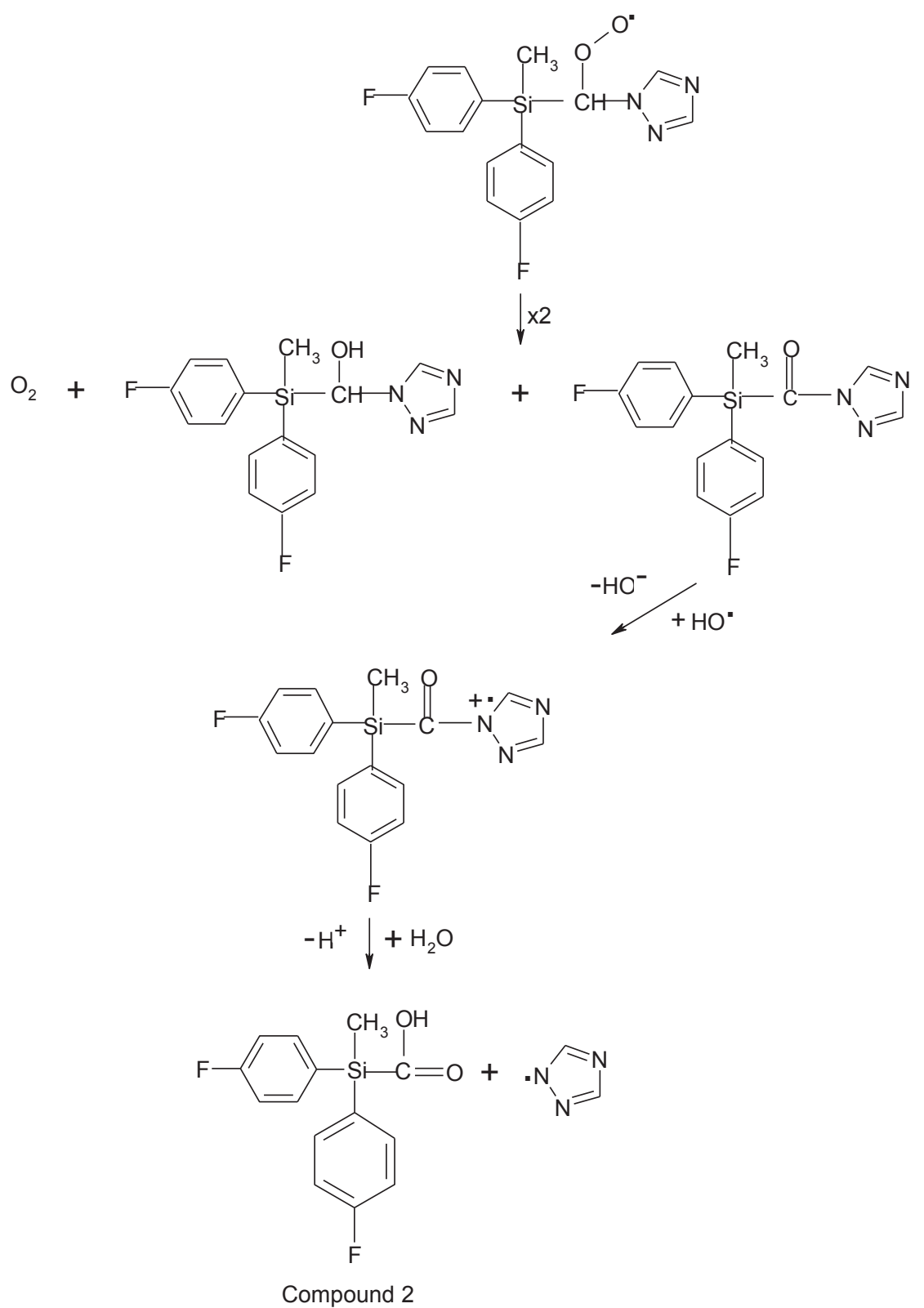

Scheme 5 .

radicals.

In the degradation process, the presence of the element silicon in the fungicide compound is essential to generate the intermediates proposed in the reaction path. The by-products identified, could further yield silicates as the final product of degradation.

\section{Acknowledgements}

DFM thanks Consejo Nacional de Investigaciones Científicas y Técnicas (CONICET, Argentina) for a graduate studentship. MCG and PC are research members of CONICET, Argentina. This research was supported by grant PICT 2012-2359 from ANPCyT. Financial support for academic interchange by the European Union (IRSES-GA-2010269128, EnvironBOS) is acknowledged.

\section{Appendix A. Supplementary data}

Supplementary data related to this article can be found at https://doi.org/10.1016/j.chemosphere.2017.09.134.

\section{References}

Amat, A.M., Arques, A., Garcia-Ripoll, A., Santos-Juanes, L., Vicente, R., Oller, I., Maldonado, M.I., Malato, S., 2009. A reliable monitoring of the biocompatibility of an effluent along an oxidative pre-treatment by sequential bioassays and chemical analyses. Water Res 43, 784-792.

Anjaneyulu, Musini, Rao, M. Jayaram Prakash, Giri, Archana, 2013. Phytochemical investigations and antibacterial activity of salacia oblonga wall ethanolic extract. Ann. Phytomed. 2 (1), 102-107.

Arce, Valeria B., Bertolotti, Sonia G., Oliveira, Fernando J.V.E., Airoldi, Claudio, Arques, Antonio, Santos-Juanes, Lucas, Gonzalez, Mónica C., Cobos, Carlos J., Allegretti, Patricia E., Mártire, Daniel O., 2012. Triplet state of 4-methoxybenzyl alcohol chemisorbed on silica nanoparticles. Photochem. Photobiol. Sci. 11 (6), 1032. https://doi.org/10.1039/c2pp05370e.

Baciocchi, Enrico, Del Giacco, Tiziana, Lapi, Andrea, 2004. Oxygenation of 
benzyldimethylamine by singlet oxygen. Products and mechanism. Org. Lett. 6 (25), 4791-4794. https://doi.org/10.1021/ol0478761. American Chemical Society.

Barone, Vincenzo, Cossi, Maurizio, 2001. Conductor solvent model. J. Phys. Chem. A 102 (97), 1995-2001.

Bosio, Gabriela, Criado, Susana, Massad, Walter, Nieto, Felipe J Rodríguez, Gonzalez, Mónica C., García, Norman A., Mártire, Daniel O., 2005. Kinetics of the interaction of sulfate and hydrogen phosphate radicals with small peptides of Glycine, alanine, tyrosine and tryptophan. Photochem. Photobiol. Sci. Offic. J. Eur. Photochem. Assoc. Eur. Soc. Photobiol. 4 (10), 840-846. https://doi.org/ $10.1039 / b 507856 c$. The Royal Society of Chemistry.

Carra, Irene, Antonio Sánchez Pérez, José, Malato, Sixto, Autin, Olivier, Jefferson, Bruce, Jarvis, Peter, 2016. Performance of different advanced oxidation processes for tertiary wastewater treatment to remove the pesticide acetamiprid. J. Chem. Technol. Biotechnol. 91 (1), 72-81. https://doi.org/ 10.1002/jctb.4577.

Choure, S.C., Bamatraf, M.M.M., Rao, B.S.M., Das, Ranjan, Mohan, H., Mittal, J.P., 1997. Hydroxylation of chlorotoluenes and cresols: a pulse radiolysis, laser flash photolysis, and product analysis study. J. Phys. Chem. A 101 (51), 9837-9845. https://doi.org/10.1021/jp971986a. American Chemical Society.

Cobos, Carlos J., Croce, Adela E., 2010. Of the CF 3 OSO 3 Radical, pp. 720-724.

Corriu, R.J.P., Guerin, B.J.L., Henner, Wang, Q., 1991. Pentacoordinate intermediates in the hydrolysis reaction of organic silicates. Organometallics 10 (4), 3200-3205. https://doi.org/10.1021/om00055a042.

Criquet, Justine, Leitner, Nathalie Karpel Vel, 2009. Degradation of acetic acid with sulfate radical generated by persulfate ions photolysis. Chemosphere 77 (2), 194-200. https://doi.org/10.1016/j.chemosphere.2009.07.040. Elsevier Ltd.

Das, S., von Sonntag, C., 1986. The Oxidation of Trimethylamine by OH Radicals in Aqueous Solution, as Studied by Pulse Radiolysis, ESR, and Product Analysis.

Dell 'Arciprete, María L., Santos-Juanes, Lucas, Arques Sanz, Antonio, Vicente, Rafael, Amat, Ana M., Furlong, Jorge P., Mártire, Daniel O., Gonzalez, Monica C., 2009. Reactivity of hydroxyl radicals with neonicotinoid insecticides: mechanism and changes in toxicity. Photochem. Photobiol. Sci. 8 (7), 1016-1023.

Dell 'Arciprete, Marı́ L., Cobos, Carlos J., Matire, Daniel O., Furlong, Jorge P., Gonzalez, Monica C., 2011. Reaction kinetics and mechanisms of neonicotinoid pesticides with sulfate radicals. New J. Chem. 35, 672-680. https://doi.org/ 10.1039/c0nj00726a.

Dell'arciprete, María L., Cobos, Carlos J., Furlong, Jorge P., Mártire, Daniel O. Gonzalez, Mónica C., 2007. Reactions of sulphate radicals with substituted pyridines: a structure-reactivity correlation analysis. Chemphyschem. A Eur. J. Chem. Phys. Phys. Chem. 8 (17), 2498-2505. https://doi.org/10.1002/ cphc. 200700456.

Dimopoulou, Myrto, Verhoef, Aart, van Ravenzwaay, Bennard, Rietjens, Ivonne M.C. M., Piersma, Aldert H., 2016. Flusilazole induces spatio-temporal expression patterns of retinoic acid-, differentiation- and sterol biosynthesis-related genes in the rat whole embryo culture. Reprod. Toxicol. 64, 77-85. https://doi.org/ 10.1016/j.reprotox.2016.04.003. Elsevier Inc.

Farag, A.T., Ibrahim, H.H., 2007. Developmental toxic effects of antifungal FlusilazoleAdmin istered by gavage to mice. Birth Defects Res. (Part B) 80, 12-17.

Faust, Bruce C., Hoigné, Jürg, 1990. Photolysis of Fe (III)-Hydroxy complexes as sources of $\mathrm{OH}$ radicals in clouds, fog and rain. Atmos. Environ. Part A, General Top. 24 (1), 79-89. https://doi.org/10.1016/0960-1686(90)90443-Q.

Frisch, M. J.; Trucks, G. W.; Schlegel, H. B.; Scuseria, G. E.; Robb, M. A.; Cheeseman, J. R.; Scalmani, G.; Barone, V.; Mennucci, B.; Petersson, G. A. 2009. “No Title.

Griessbach, E.F.C., Lehmann, R.G., 1999. Degradation of polydimethylsiloxane fluids in the environment - a review. Chemosphere 38 (6), 1461-1468. https://doi.org/ 10.1016/S0045-6535(98)00548-7.

Guillard, C., Horikoshi, S., Watanabe, N., Hidaka, H., Pichat, P., 2002. Photocatalytic degradation mechanism for heterocyclic derivatives of triazolidine and triazole. J. Photochem. Photobiol. A Chem. 149 (1-3), 155-168. https://doi.org/10.1016/ S1010-6030(01)00653-0.

Hasegawa, Eietsu, Wei Xu, Patrick S Mariano, and Jin-uk Kim. 1988. "Eietsu Hasegawa,? Wei Xu,? Patrick S. Mariano,,,? Ung-Chan," no. 6.

Hiller, K.O., Asmus, K.D., 1983. Formation and reduction reactions of.alpha.-amino radicals derived from methionine and its derivatives in aqueous solutions. J. Phys. Chem. 87 (19), 3682-3688. https://doi.org/10.1021/j100242a022. American Chemical Society.

Hosseinihashemi, Seyyed Khalil, Anooshei, Hamidreza, Aghajani, Hamed, Salem, Mohamed Z.M. 2015. Chemical composition and antioxidant activity of extracts from the inner bark of Berberis Vulgaris stem. BioResources 10 (4), 7958-7969. https://doi.org/10.15376/biores.10.4.7958-7969.

Ito, Takeo, Morimoto, Shota, Fujita, Shin ichi, Nishimoto, Sei ichi, 2009. Radical intermediates generated in the reactions of L-Arginine with hydroxyl radical and sulfate radical anion: a pulse radiolysis study. Radiat. Phys. Chem. 78 (4), 256-260. https://doi.org/10.1016/j.radphyschem.2009.01.005.

Kathirvel, A., Rai, A.K., Maurya, G.S., Sujatha, V., 2014. Dryopteris cochleata rhizome: a nutritional source of essential elements, phytochemicals, antioxidants and antimicrobials. Int. J. Pharm. Pharm. Sci. 6 (Suppl. 2), 179-188.

Kim, Soo-Myung, Vogelpohl, Alfons, 1998. Degradation of organic pollutants by the photo-fenton-process. Chem. Eng. Technol. 21 (Ii), 187-191. https://doi.org/ 10.1002/(SICI)1521-4125(199802)21:2<187::AID-CEAT187>3.0.CO;2-H.

Kozicki, Marek, Filipczak, Katarzyna, Rosiak, Janusz Marian, 2003. Reactions of hydroxyl radicals, $\mathrm{H}$ atoms and hydrated electrons with $\mathrm{N}, \mathrm{N}^{\prime}$-Methylenebisacrylamide in aqueous solution. A pulse radiolysis study. Radiat. Phys. Chem. 68 (5), 827-835. https://doi.org/10.1016/S0969-806X(03)00311-6.

Lalevée, J., Graff, B., Allonas, X., P Fouassier, J., 2007. Aminoalkyl radicals: direct observation and reactivity toward oxygen, 2,2,6,6-tetramethylpiperidine- $\mathrm{N}$ oxyl, and methyl acrylate. J. Phys. Chem. A 111 (30), 6991-6998. https://doi.org/ 10.1021/jp071720w. American Chemical Society.

Le Campion, Laurence, Giannotti, Charles, Ouazzani, Jamal, 1999. Photocatalytic degradation of 5-nitro-1,2,4-triazol-3-one NTO in aqueous suspention of $\mathrm{TiO}_{2}$. Comparison with fenton oxidation. Chemosphere 38 (7), 1561-1570. https:/ doi.org/10.1016/S0045-6535(98)00376-2.

Lhomme, Ludovic, Brosillon, Stephan, Wolbert, Dominique, 2007. Photocatalytic degradation of a triazole pesticide, cyproconazole, in water. J. Photochem. Photobiol. A Chem. 188 (1), 34-42. https://doi.org/10.1016 j.jphotochem.2006.11.015.

Luke, T.L., Mohan, H., Manoj, V.M., Manoj, P., Mittal, J.P., Aravindakumar, C.T., 2003 Reaction of sulphate radical anion (SO.4-) with hydroxy-and methyl-substituted pyrimidines: a pulse radiolysis study. Res. Chem. Intermed. 29 (4), 379-391.

Luo, Shuang, Wei, Zongsu, Dionysiou, Dionysios D., Spinney, Richard, Hu, Wei-Ping Chai, Liyuan, Yang, Zhihui, Ye, Tiantian, Xiao, Ruiyang, 2017. Mechanistic insight into reactivity of sulfate radical with aromatic contaminants through singleelectron transfer pathway. Chem. Eng. J. 327, 1056-1065. https://doi.org/ 10.1016/j.cej.2017.06.179. Elsevier B.V.

Mastovska, Katerina, 2007. Food and Agriculture Organization of the United Nations. Eastern Regional Research Center, Agricultural Research Service, USA http://www.fao.org/fileadmin/templates/agphome/documents/Pests_Pesticide s/JMPR/Evaluation07/Flusilazole.pdf.

Navarro, Simón, Fenoll, José, Vela, Nuria, Ruiz, Encarnación, Navarro, Ginés, 2011 Removal of ten pesticides from leaching water at pilot plant scale by photofenton treatment. Chem. Eng. J. 167 (1), 42-49. https://doi.org/10.1016/ j.cej.2010.11.105.

Neta, P., Huie, Robert E., Ross, Alberta B., 1988. Rate constants for reactions of inorganic radicals in aqueous solution. J. Phys. Chem. Ref. Data 17 (3). https:// doi.org/10.1063/1.555808. AIP Publishing: 1027.

Ozakca, Dilek Unal, Silah, Hulya, 2013. Genotoxicity effects of flusilazole on the somatic cells of Allium Cepa. Pesticide Biochem. Physiol. 107 (1), 38-43. https:// doi.org/10.1016/j.pestbp.2013.05.001. Elsevier Inc.

Padmaja, S., Alfassi, Z.B., Neta, P., Huie, R.E., 1993. Rate constants for reactions of SO4\$ radicals in acetonitrile. Int. J. Chem. Kinet. 25 (3), 193-198. https://doi.org/ 10.1002/kin.550250307.

Roberts, Terry R., Hutson, David H., 1990. In: Terry, R., Roberts, Hutson, David H. (Eds.), Metabolic Pathways of Agrochemicals. Part2: Insecticides and Fungicides, first ed. Royal Society of Chemistry, Cambridge.

Ross, W. G. Mallard, W. P. Helman, G. V. Buxton, R. E. Huie, P. Neta. 1998. “No Title.” NDRL-NIST Solution Kinetics Database, Ver. 3.0. Notre Dame Radiation Laboratory, Notre Dame, IN, US and National Institute of Standards and Technology, Gaithersburg,MD, US. http://kinetics.nist.gov/solution/.

San Roman, Enrique, Gonzalez, Monica C., 1989. Analysis of spectrally resolved kinetic data and time-resolved spectra by bilinear regression. J. Phys. Chem. 93, 3532-3536.

Schmider, Hartmut L., Becke, Axel D., 1998. Optimized density functionals from the extended G2 test set. J. Chem. Phys. 108 (23), 9624-9631. https://doi.org/ 10.1063/1.476438.

Sumalekshmy, S., Gopidas, K.R., 2005. Reaction of aromatic amines with $\mathrm{Cu}(\mathrm{ClO} 4) 2$ in acetonitrile as a facile route to amine radical cation generation. Chem. Phys. Lett. 413 (4-6), 294-299. https://doi.org/10.1016/j.cplett.2005.06.041.

Suresh, Das, Suresh, V., 2001. Electron-transfer reactions of amines. In: Balzani, V. (Ed.), Electron Transfer in Chemistry. Wiley-VCH, New York, pp. 379-456.

Trovó, Alam Gustavo, Melo, S.A.S., Nogueira, R.F.P., 2008. Photodegradation of the pharmaceuticals amoxicillin, bezafibrate and paracetamol by the photo-fenton process-application to Sewage treatment plant effluent. J. Photochem. Photobiol. A Chem. 198 (2-3), 215-220. https://doi.org/10.1016/ j.jphotochem.2008.03.011.

Tuazon, Ernesto C., Aschmann, Sara M., Roger, Atkinson, 2000. Atmospheric degradation of volatile methyl-silicon compounds. Environ. Sci. Technol. 34, 1970-1976

Wang, Chi Wei, Liang, Chenju, 2014. Oxidative degradation of TMAH solution with UV persulfate activation. Chem. Eng. J. 254, 472-478. https://doi.org/10.1016/ j.cej.2014.05.116. Elsevier B.V. 